\title{
Learning difficulties in Moroccan students related of communication disorders and using of the french language: results of an investigation of chemistry students
}

\author{
SOUBHI Fatim Zahra ${ }^{1^{\star}}$, TOURI Bouzekri ${ }^{1}$, Lima Laurent ${ }^{2}$, KNOUZI \\ Noureddine $^{1}$, TALBI Mohammed ${ }^{1}$ KASOUR Radouane ${ }^{1}$ \\ ${ }^{I}$ University Hassan II Mohammedia-Casablanca; Observatory of Research in Didactics and University \\ Pedagogy (ORDIPU), Morocco. \\ ${ }^{2}$ University Pierre Mendès France Grenoble, Laboratory of Educational Sciences, France
}

\begin{abstract}
Our research is intended to provide data on learning difficulties within students from scientific majors and the causes of school failure and abandon phenomena in the university. In this research, we are interested in the study of communication disorders and difficulties that these disorders may result in beyond the only language aspects. 519 chemistry students belonging to the Faculty of Sciences Ben M'sik at the University Hassan II Mohammedia -Casablanca participated in the survey. They are aged between 17 and 23 years and suffer no physical or mental disability. The questionnaire consists of 101 questions grouped into 8 themes. Our results indicate that communication disorders impact students' self-confidence. Therefore, we can think that through their influence on self-confidence, these disorders cause a decrease in academic performance. High self-confidence is associated with the retention and academic success while a low self-confidence is associated with school failure and abandonment.
\end{abstract}

Keywords: academic performance - communication disorders- learning difficulties - self-confidence.

\section{Introduction and problem}

This survey was designed to identify, explore the effects of psycho-communication and using for french language within Moroccan students studying chemistry. focusing on communication disorders and the difficulties that these disorders may lead beyond only language aspects. Universities with 30,000 students tend not to have more than 3 GPs and no healthcare nurses. Our investigation has tried to focus on health issues within universities and namely the colleges of hard sciences - the "Faculté des sciences Ben Msik at Casablanca Morocco".

a. Participants:

\section{Method}

The surveyed population consists of students from 1st, 2nd, 3rd year of university, chemistry. Our sample consisted of 519 students, representing three semesters. This is S2, S4, and S6.

Tab1 Distribution by semestre

\begin{tabular}{cccc}
\hline & Semester S2 & Semester S4 & Semester S6 \\
\hline Female & 190 & 71 & 47 \\
Male & 164 & 27 & 12 \\
Total & 354 & 98 & 59 \\
\hline
\end{tabular}

Both semesters S4 and S6 have an effective majority Female (respectively $72 \%$ and $80 \%$ ). However, the proportion of male students is higher in S2 (46\% male / 54\% female) (Chi2 $=21.7, \mathrm{p}>0.001)$. The average age of students is 20 years; there was no significant difference between male and female students.

b. Measures:

The questionnaire consists of 101 questions grouped in 08 themes. The first is the academic membership of the student (university, discipline, BA). The second theme on the school career (change of discipline, late at school ...), the third theme focuses on the frequency of contact with teachers, families and students, the fourth theme aims to provide data on the behavior of student learning, then there is the theme of self-esteem that integrates across Coopersmith then the theme on the integration of graduates into the industry outlook, and the theme questioning the personal data (gender, age, siblings, civil status). The final theme focuses on health in 4 areas: general health, communication disorders, disorders impact, health practices and addictive behaviors. 
As our study will focus on the linked between communication disorder and self-esteem, we will only detail the measures assessing these two aspects.

$>\quad$ Disorder communication is based on two types :

- $\quad$ Hearning disorder

- $\quad$ Voice disorder

$>\quad$ Inventory questionnaire Coopersmith Self-Esteem is the test that was constructed to measure evaluative attitudes towards oneself in social, Family and school.

The 42 Selected items is the distribution as follows:

General measure (18 items) :1,2,7,8,13,14,15,19,20,22,23,27,32,36,37,40,41,42.

$\bullet$

Social measure (6 items) : 3, 9, 16, 24, 28,38.

$\bullet$

$\bullet$

Family measure (6 items) : 4, 10, 17, 21, 29,33.

School measure (6 items) : 6, 12, 26, 31, 35,39.

A lie measure (6 items) : 5, 11, 18, 25, 30,34.

This theme must be answer to each statement by checking the appropriate box :"Like me" or "not like me ".

Five thematic indices of self-esteem are produced: These are the general self-esteem, social, educational, family and lies.

The notes to the different subscales, and the total score used to assess in which areas and how the subjects have a positive image of themselves.

\section{c. Procedure}

The survey was conducted in April, May, June 2013. The questionnaires were distributed to students at the end of a course. A period of 10 minutes was devoted to the presentation of the questionnaire, its goals and how to respond. Then, the following 25 minutes were allowed for students to complete the questionnaire. The questionnaires were collected immediately by the experimenter.

\section{d. Analysis:}

After data collection (June 2013), we used SPSS software for data processing and analysis. Our interest in this survey was focused on health theme. The first question "How do you rate the state of your health" gave us important information that can be represented as follow:

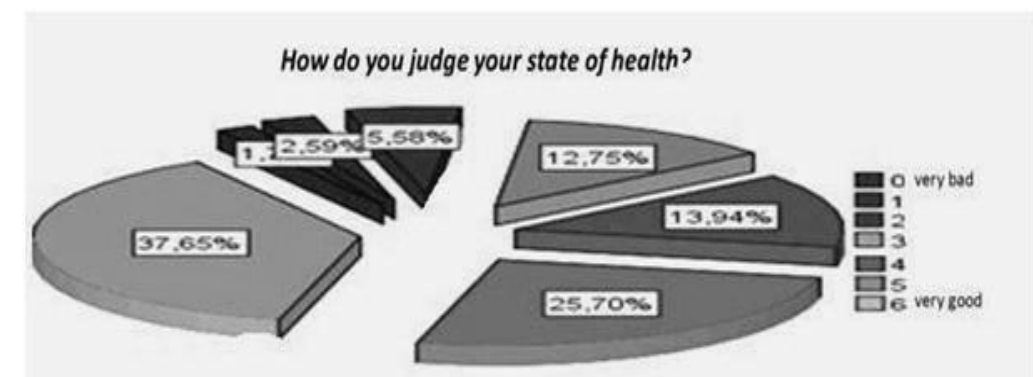

Graph 1: Statistics for the question "How do you judge your state of health? (from 0: very bad to 6 very good)

In this sample, only $9.96 \%$ of students believe that the state of their health is bad, the majority $52.39 \%$ thinks that it is either fairly well or well, $37.65 \%$ said they had a very good health. Therefore, $90.04 \%$ of students have a positive view of their own health.

Students were asked about the different communication disorders they were suffering from. The following chart shows the four main types of communication disorders discovered within students:

Students were asked about the different communication disorders they were suffering from. The following chart shows the four main types of communication disorders discovered within students: 


\section{Communication disorders}

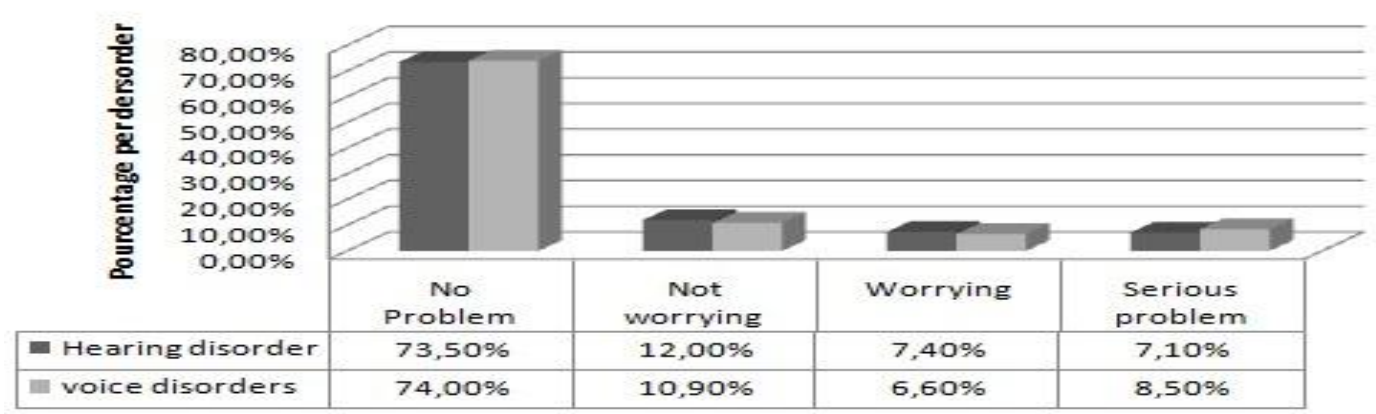

Graph 2: Percentage of communication disorders of hard science students in Morocco

The results indicate that more than one in four $(26.5 \%)$ is affected by hearing impairment. Among the students affected by such disorders, $26 \%$ say they suffer serious problems, $28 \%$ think these problems are worrying and $45 \%$ consider these problems are not worrying.

$26 \%$ of students are involved in this type of disorder. Among students who report being affected by a voice disorder, a quarter consider it a worrying problem $(25 \%)$ and $32 \%$ of serious problems. Almost half (41 $\%)$ say that the voice problem is not worrying.

\section{Hearing Disorders:}

\section{Impact Of Communication Disorder}

We compared the mean of students not affected by the disorder with those affected by hearing impairment. The comparison indicates that the average of student at the general level of self-esteem is 9, while those impacted by the disorder evaluate their self-confidence at $8.2(\mathrm{~F}=8.79, \mathrm{p}=0.03)$, which implies a negative impact of the disorder on the general scale. On the contrary, on the level of other scales, averages are close; we can conclude only that there is a negative effect of hearing impairment on general self-esteem. However, the average student affected by the problem at the family level is high compared to the average of other students $(2.37$ and 2.04 respectively, $F=4.10 \mathrm{p}=0.02)$. A difference in the effect of increased support within the family towards the students affected by this disorder can be noticed (Dinther, 2011).

Tab 2 Average scores of Coopersmith self-esteem scale depending on the presence or absence of a hearing

\begin{tabular}{|c|c|c|c|c|c|c|}
\hline Scale & H.D & $\mathbf{N}^{\circ}$ & Average & $\begin{array}{l}\text { Standard } \\
\text { deviation }\end{array}$ & $\mathbf{F}$ & $\mathbf{P}$ \\
\hline \multirow[t]{3}{*}{ General } & No problem & 287 & 8,9617 & 2,15044 & \multirow{3}{*}{8,797} & \multirow{3}{*}{, 003} \\
\hline & Problem & 99 & 8,1818 & 2,30511 & & \\
\hline & Total & 386 & 8,7617 & 2,21452 & & \\
\hline \multirow[t]{3}{*}{ Family } & No problem & 312 & 2,04487 & 0,981127 & \multirow{3}{*}{10,004} & \multirow{3}{*}{,002 } \\
\hline & Problem & 121 & 2,3719 & 1,073408 & & \\
\hline & Total & 433 & 2,13626 & 1,017168 & & \\
\hline \multirow[t]{3}{*}{ Social } & No problem & 301 & 2,2691 & 1,04754 & \multirow{3}{*}{, 053} & \multirow{3}{*}{, 817} \\
\hline & Problem & 112 & 2,2411 & 0,9977 & & \\
\hline & Total & 413 & 2,2615 & 1,03314 & & \\
\hline \multirow[t]{3}{*}{ School } & No problem & 292 & 3,3014 & 1,24558 & \multirow{3}{*}{, 025} & \multirow{3}{*}{, 875} \\
\hline & Problem & 115 & 3,2435 & 1,31517 & & \\
\hline & Total & 407 & 3,285 & 1,26427 & & \\
\hline \multirow[t]{3}{*}{ Lie } & No problem & 306 & 3,1405 & 1,26615 & \multirow{3}{*}{2,281} & \multirow{3}{*}{, 132} \\
\hline & Problem & 114 & 3,3509 & 1,26199 & & \\
\hline & Total & 420 & 3,1976 & 1,26698 & & \\
\hline
\end{tabular}

\section{Voice Disorders:}

We compared the average of students not affected by the disorder in those affected by the speech disorder and we found that the average student in self-esteem is usually 9 , while those impacted by the disorder evaluate their self-confidence averaged at $8.07(\mathrm{~F}=12.16, \mathrm{p}=0.001)$, which implies negative impact of the disorder on the general scale. The same report at the school level, students having disorder assess their selfconfidence school at 3.02 while the average of those not impacted is $3.34(\mathrm{~F}=4.95, \mathrm{p}=0.027)$. Students feel they have more obstacles in academic achievement (Touri\& Marquardt, 2013); it may have originated from problems of personal development and obstacle in expressing oneself in public speaking. 
Learning difficulties in Moroccan students related of communication disorders and using of the french language: results of an investigation of chemistry students

Tab 3 Average scores of Coopersmith self-esteem scale depending on the presence or absence of a voice disorder.

\begin{tabular}{|c|c|c|c|c|c|c|}
\hline Scale & Voice Disoder & $\mathbf{N}^{\circ}$ & Average & $\begin{array}{l}\text { Standard } \\
\text { deviation }\end{array}$ & $\mathbf{F}$ & $\mathbf{P}$ \\
\hline \multirow[t]{3}{*}{ General } & No problem & 290 & 8,9655 & 2,15141 & & \\
\hline & Problem & 99 & 8,0707 & 2,35715 & 12,165 & 001 \\
\hline & Total & 389 & 8,7378 & 2,23679 & & \\
\hline \multirow[t]{3}{*}{ Family } & No problem & 321 & 2,09034 & 0,997466 & & \\
\hline & Problem & 117 & 2,22222 & 1,091591 & 1,518 & ,219 \\
\hline & Total & 438 & 2,12557 & 1,02385 & & \\
\hline \multirow[t]{3}{*}{ Social } & No problem & 305 & 2,259 & 1,01395 & & \\
\hline & Problem & 114 & 2,307 & 1,16077 & 250 & ,617 \\
\hline & Total & 419 & 2,2721 & 1,0547 & & \\
\hline \multirow[t]{3}{*}{ School } & No problem & 300 & 3,34 & 1,25818 & & \\
\hline & Problem & 110 & 3,0273 & 1,29543 & 4,953 & 027 \\
\hline & Total & 410 & 3,2561 & 1,27426 & & \\
\hline \multirow[t]{3}{*}{ Lie } & No problem & 311 & 3,1318 & 1,2334 & & \\
\hline & Problem & 112 & 3,3571 & 1,4005 & 2,627 &, 106 \\
\hline & Total & 423 & 3,1915 & 1,28193 & & \\
\hline
\end{tabular}

IV. Judgment Forms On The Use Of The French Language.

The majority of students $85 \%$ reported being victims of the use of the French language, $25 \%$ say they have big problems with French language, $60 \%$ believe that the use of the French language poses some problems, however $14 \%$ say the use of the French language is not a problem (see Figure 3). Language difficulties appear to be due to language change, since the use of the French language in science subjects started at the university.

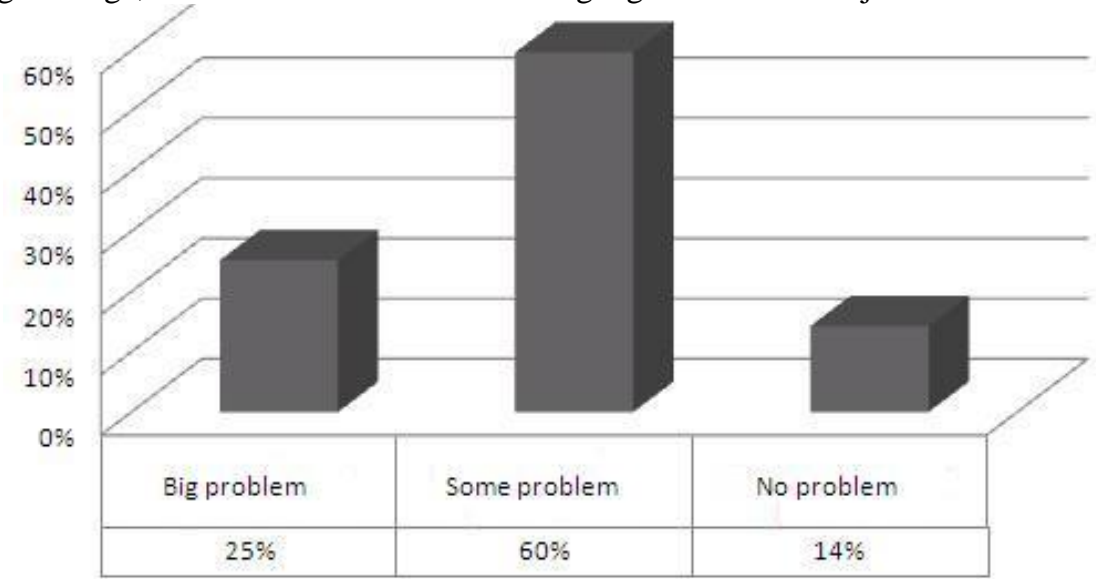

Graph 3 The use of the French language at the University

\section{Conclusions}

Our results indicate that the majority of students $90.04 \%$ have a positive view of their own health, $85 \%$ reported being victims of the use of the French language.Based on these results we can see the impact of communication disorder on self-esteem, school, and we see that the problem are considered factors of learning difficulties.

\section{References}

[1]. Dyck, M., \& Piek, J. (2010). How To Distinguish Normal From Disordered Children With Poor Language Or Motor Skills. International Journal Of Language \& Communication Disorders DETAILS.

[2]. Fey, M. E., Catts, H.W. \& Larrivee, L. S. (1995) Preparing Preschoolers For The Academic And Social Challenges Of School. In J. Windsor (Eds.), Language Impairment And Social Competence. Language Intervention: Preschool Through The Elementary Years. Baltimore, MD: Paul H Brookes Publishing

[3]. Glozman, J. M. (1987). Communication Disorders And Personality. New York: Plenum Publishers.

[4]. Trevarthen, C. (2008). Intuition For Human Communication. In S. M. Zeedyk (Eds.), Promoting Social Interaction For Individuals With Communicative Impairments:Making Contact.. London, UK: Jessica Kingsley Publishers.

[5]. Self-Efficacy: Toward A Unifying Theory Of Behavioral Change,Albert Bandura, Stanford University.

[6]. Self-Efficacy Beliefs In Academic Setting , Frank Pajares, Emory University

[7]. Ellen L. Usher, Frank Pajares (2009). « Sources Of Self-Efficacy In Mathematics: A Validation Study ». Contemporary Educational Psychology.

[8]. KASOUR Radouane (2014) Etude épistémologique et didactique des obstacles et difficultés d'apprentissage: cas d'algébre linéaire p 116 